\title{
Age differentiation of the perception of toponyms (based on the toponyms Uglich, Tutaev, Pereslavl-Zalessky)
}

\author{
A. A. Talitskaya ${ }^{1}$, K. A. Lepakova ${ }^{1}$
}

${ }_{1}^{1}$ P. G. Demidov Yaroslavl State University, 14 Sovetskaya str., Yaroslavl 150003, Russian Federation

DOI: $10.18255 / 2412-6519-2021-1-96-107$

Research Article

Full text in Russian

The article examines the peculiarities of the language consciousness of the residents of the Yaroslavl region in the age aspect. The research is carried out on the material of the toponyms Uglich, Tutaev and Pereslavl-Zalessky. A psycholinguistic experiment was conducted, including these stimuli, according to its results, associative fields were compiled for each toponym for each age group separately. As a result of semantic interpretation of the obtained associative fields, all associative reactions are divided into semantic groups. The number of reactions for each semantic group is specified. As a result of a comparative analysis of the semantic groups formed during the interpretation of reactions to the toponym Uglich, common semantic groups were identified for all age categories: «Generic geographical name», «Connection with brands of products of various kinds». For the stimulus Tutaev such semantic groups become «Generic geographical name», «Emotions, experiences, subjective estimate, Indicating to the city of various kinds of objects», for the stimulus Pereslavl-Zalessky - «Generic geographical name», «Connection name of the city with natural objects», «Emotions, experiences, subjective estimate», «Indication of various types of urban objects», «The relationship with well-known personalities». In addition, for each toponym, unique semantic groups were identified that are characteristic of a certain age category.

Keywords: language consciousness; associative field; semantic group; Uglich; Tutaev; PereslavlZalessky; psycholinguistic experiment

INFORMATION ABOUT THE AUTHORS

Talitskaya, Anna A. $\quad$ E-mail: cliver_08@bk.ru

(correspondence author) Cand. Sc. (Philology), Associate Professor

\begin{tabular}{l|l} 
Lepakova, Ksenia A. & E-mail: ksyusha-lepakova@yandex.ru \\
Student
\end{tabular}

For citation: Talitskaya A. A., Lepakova K. A. Age differentiation of the perception of toponyms (based on the toponyms Uglich, Tutaev, Pereslavl-Zalessky) // Social'nye i gumanitarnye znanija. 2021. Vol. 7, No 1. P. 96-107. (in Russ.)

(C) Talitskaya A. A., Lepakova K. A., 2021

This is an open access article under the CC BY license (https://creativecommons.org/licenses/by/4.0/) 


\title{
Возрастная дифференциация восприятия топонимов (на материале топонимов Углич, Тутаев, Переславль-Залесский)
}

\author{
А. А. Талицкая ${ }^{1}$, К. А. Лепакова ${ }^{1}$
}

1Ярославский государственный университет им. П.Г. Демидова, ул. Советская, 14, Ярославль, 150003, Российская Федерация

DOI: $10.18255 / 2412-6519-2021-1-96-107$

УДК 81

Научная статья

Полный текст на русском языке

В статье исследуются особенности языкового сознания жителей Ярославской области в возрастном аспекте. Исследование осуществляется на материале топонимов Углич, Тутаев и Переславль-Залесский. Был проведен психолингвистический эксперимент, включающий указанные стимулы, по его результатам составлены ассоциативные поля для каждого топонима для каждой возрастной группы отдельно. В результате семантической интерпретации полученных ассоциативных полей все ассоциативные реакции разделены на семантические группы. Указано количество реакций для каждой семантической группы. В результате сопоставительного анализа семантических групп, сформированных при интерпретации реакций на топоним Углич, были выявлены общие семантические группы для всех возрастных категорий: «Родовое географическое наименование», «Связь с брендами продукции различного рода». Для стимула Тутаев такими семантическими группами стали «Родовое географическое наименование», «Эмоции, впечатления, субъективная оценка», «Указание на городские объекты разного рода», для стимула ПереславльЗалесский - «Родовое географическое наименование», «Связь названия города с природными объектами», «Эмоции, впечатления, субъективная оценка», «Указание на городские объекты разного рода», «Связь с известными личностями». Кроме того, для каждого топонима были выявлены уникальные семантические группы, характерные для определенной возрастной категории.

Ключевые слова: языковое сознание; ассоциативное поле; семантическая группа; Углич; Тутаев; Переславль-Залесский; психолингвистический эксперимент

ИНФОРМАЦИЯ ОБ АВТОРАХ

Талицкая, Анна Александровна (автор для корреспонденции)

Лепакова, Ксения Александровна
Email: cliver_08@bk.ru

Кандидат филологических наук, доцент, доцент кафедры общей и прикладной филологии

Email: ksyusha-lepakova@yandex.ru

Магистрант факультета филологии и коммуникации

Для цитирования: Талицкая А. А., Лепакова К. А. Возрастная дифференциация восприятия топонимов (на материале топонимов Углич, Тутаев, Переславль-Залесский) // Социальные и гуманитарные знания. 2021. Том 7, № 1. С. 96-107.

(C) Талицкая А. А., Лепакова К. А., 2021

Статья открытого доступа под лицензией СС BY (https://creativecommons.org/licenses/by/4.0/) 
Ассоциативный эксперимент - наиболее разработанный метод изучения языкового сознания и один из самых распространенных способов получения экспериментальных данных в современной психолингвистике. По мнению В. П. Белянина [1], с помощью ассоциативного эксперимента исследователи выявляют психологический компонент в значении слова-стимула, что позволяет вскрыть «объективно существующие в психике носителя языка семантические связи слов».

Современные исследователи в области психолингвистики с помощью данного метода изучают семантику лексем, в частности, интерес для научных работ представляют имена собственные [2]. Описание топонимической лексики является одним из спорных и обсуждаемых вопросов для различных областей языкознания.

Психолингвисты рассматривают географические названия с позиции человеческого сознания. По мнению А.В. Рудаковой, «психолингвистические методы исследования семантики онимов выявляют узуальные и окказиональные семантические компоненты, актуальные для языкового сознания носителей языка» [3]. Также исследователь на основе своих научных изысканий делает вывод, что имена собственные имеют конкретную семантику. На освоение топонимической лексики в языковом сознании носителей языка влияют различные экстралингвистические факторы: гендерные, возрастные, региональные. В нашем исследовании мы обратились к возрастному аспекту в восприятии топонимов, так как этот фактор оказывает наибольшее влияние на освоение топонимов в языковом сознании носителя языка и на осведомленность реципиентов о характерных признаках имени собственного.

Для исследования мы выбрали названия центров муниципальных районов Ярославской области: Ярославль, Рыбинск, Переславль-Залесский, Углич, Тутаев, Большое Село, Брейтово, Любим, Пошехонье и др. Объем статьи не позволяет описать данные, полученные при анализе всех стимулов. Для исследования мы выбрали топонимы самых крупных по численности населения центров муниципальных объектов Ярославской области после городов Ярославль и Рыбинск. Такими стимулами стали города Углич, Тутаев и Переславль-Залесский.

В данной статье мы проводим сравнение реакций, полученных от респондентов разных возрастных групп, которые можно разделить на три категории: учащиеся школ и учреждений среднего профессионального образования в возрасте до 17 лет (младшая возрастная группа); молодые люди в возрасте от 18 до 25 лет (средняя возрастная группа); взрослые люди в возрасте от 26 до 80 лет (старшая возрастная группа).

Цель статьи - дать психолингвистическое описание лексем Углич, Тутаев и Переславль-Залесский и рассмотреть полученные результаты, учитывая возрастной аспект.

Респондентам было предложено принять участие в психолингвистическом эксперименте и дать на предложенные слова первую ассоциацию. Необходимо было указать свой пол, возраст и социальное положение. В качестве материала исследования нами были использованы данные свободных ассоциативных экспериментов, проведенных в 2019-2020 годах.

Всего в психолингвистическом эксперименте приняли участие 259 человек, жители Ярославля и Ярославской области в возрасте от 13 до 80 лет.

Результаты ассоциативного эксперимента мы представили в виде ассоциативных полей стимулов по каждой возрастной группе отдельно.

Рассмотрим ассоциативные поля каждого стимула, составленные на основе реакций, полученных от учащихся школ и учреждений среднего профессионального образования в возрасте до 17 лет. 


\section{МЛАДШАЯ ВОЗРАСТНАЯ ГРУППА Ассоциативное поле топонима Углич}

Углич 50 - город 8; вода 5; уголь 4; угли 3; водичка; городской поселок; город углов; дед мороз; деревня; золото; источник; каникулы; мамина работа; небольшой город; отель; оффники; поездка; природа; тетя; углеводы; угличская - название питьевой воды; угличское масло; угол; утюг; хороший город; черный город; шахта угля 1.

Всего 43 реакции, из них различных - 28. Отказ - 7.

Ассоциативные реакции были распределены нами по семантическим группам, которые мы расположили в порядке убывания общего количества реакций:

1. Реакции, которые сходны со стимулом по фонетической структуре: уголь 4; угли 3; город углов; угол; утюг; углеводы; черный город; шахта угля 1.

Всего 11 реакций.

2. Связь с брендом пищевых продуктов, питьевой воды: вода 5; минералка; водичка; источник; угличское масло; угличская - название питьевой воды 1.

Всего 10 реакций.

3. Родовое географическое наименование: город 8; городской поселок; деревня 1.

Всего 10 реакций.

4. Эмоции, впечатления, субъективная оценка: небольшой город; хороший город 1.

Всего 2 реакции.

Реакции, связанные с конкретными личными впечатлениями и опытом испытуемых и не поддающиеся интерпретации: Дед Мороз; золото; каникулы; мамина работа; отель; оффники; поездка; природа; тетя 1.

Интересно, что от респондентов мы получили большее количество реакций, которые сходны со стимулом по фонетической структуре $(5,5 \%)$. В эту семантическую группу вошли также реакции, возникшие от ассоциации топонима со словом «уголь» (черный город; шахта угля 1).

Часть респондентов связывает образ Углича с брендами пищевых продуктов, которые производятся на предприятиях города. Также участники эксперимента связывают название города с родовым географическим наименованием. При этом удалось выявить указания на различные типы населенных пунктов. Обе семантические группы стали одинаковыми по количеству полученных реакций (5 \%).

Также реципиенты связывают название города с личными оценками, эмоциями и впечатлениями, которые вызваны сложившимся представлением об Угличе.

Реакций, не поддающиеся интерпретации и связанные с конкретным опытом испытуемых, часто указывают на знакомых респондентам людей, и реципиенты связывают конкретные события в своей жизни с названием города.

Нам удалось выявить как синтагматические ассоциации (небольшой город; хороший город 1), так и парадигматические (город 8; вода 5).

Отметим, что 3,5 \% респондентов не дали реакции на данный стимул.

\section{Ассоциативное поле топонима Тутаев}

Тутаев 50 - город; дом 4; деревня; дыра; мусор; родина; тутка 2; бесячий пацан с тренировки; бор; городок; днище; дно; друг; друзья; козявки; Мамаев; мой родной город; музыка; не был там; овечка; родной город; село; столица; там живет тетя; Туношна; тутаевский район; хата; церковь; что?; чудное место; это мини-город 1.

Всего 42 реакции, из них различных - 31. Отказ - 8. 
Ассоциативные реакции были распределены нами по семантическим группам, которые мы расположили в порядке убывания общего количества реакций:

1. Родовое географическое наименование: город 4; деревня 2; городок; село; Тутаевский район; это мини-город 1.

Всего 10 реакций.

2. Восприятие Тутаева как дома, родного места: дом 4; родина 2; мой родной город; родной город 1.

Всего 8 реакций.

3. Эмоции, впечатления, субъективная оценка: дыра 2; мусор; днище; дно; столица; чудное место 1.

Всего 7 реакций.

4. Интерпретация официального наименования города: Тутка 2.

Всего 2 реакции.

5. Указание на городские объекты разного рода: бор; церковь 1.

Всего 2 реакций.

6. Указание на другие топонимы: Туношна 1.

Всего 1 реакция.

Реакции, связанные с конкретными личными впечатлениями и опытом испытуемых и не поддающиеся интерпретации: бесячий пацан с тренировки; друг; друзья; козявки; Мамаев; музыка; не был там; овечка; там живет тетя; хата; что? 1.

Среди реципиентов младшей возрастной группы наиболее объемной по числу реакций (5 \%) стала семантическая группа «Родовое географическое наименование» и самой частотной ассоциацией стала лексема город (4 реакции).

Также реципиенты ассоциируют город с родным домом и с семьей (4 \%).

Кроме того, была выделена семантическая группа, включающая субъективные впечатления о городе. Нам удалось выявить реакции (1 \%), которые являются неофициальным названием города (Тутка 2). В разговорной речи молодого поколения часто используется такое наименование Тутаева.

Единичные реакции, которые мы получили, связывают наименование города с природными объектами, достопримечательностями и с другими населенными пунктами.

Стоит отметить, что у 4 \% опрошенных топоним Тутаев не вызвал никаких ассоциаций.

\section{Ассоциативное поле топонима Переславль-Залесский}

Переславль-Залесский 50 - город 7; лес 5; зеленый; зелень; президент Зеленский 2; Александр Петров; Антон; Зеленский; Маша; бабушка; бар; деревня; Залеский Переславль; зеленый город; красивый город; креативность; Невский; перелесок; поезд; приезд к другу; пряник; работа; разведение собак; собор; усадьба 1.

Всего 38 реакций, из них различных - 26. Отказ - 12.

Ассоциативные реакции были распределены нами по семантическим группам, которые мы расположили в порядке убывания общего количества реакций:

1. Родовое географическое наименование: город 7.

Всего 7 реакций.

2. Связь названия города с лесом: лес 5; перелесок 1.

Всего 6 реакций.

3. Восприятие города как места, где много зелени, деревьев: зеленый; зелень 2; зеленый город 1.

Всего 5 реакций. 
4. Реакции, которые сходны со стимулом по фонетической структуре: президент Зеленский 2; Зеленский; Залеский Переславль 1.

Всего 4 реакции.

5. Эмоции, впечатления, субъективная оценка: деревня; красивый город; креативность 1.

Всего 3 реакции.

6. Указание на городские объекты разного рода: собор; усадьба 1.

Всего 2 реакции.

7. Связь с известными личностями: Александр Петров; Невский 1.

Всего 2 реакции.

Реакции, связанные с конкретными личными впечатлениями и опытом испытуемых и не поддающиеся интерпретации: Антон; бабушка; бар; Маша; поезд; приезд к другу; пряник; работа; разведение собак 1.

От респондентов мы получили большее количество реакции $(3,5 \%)$, которые указывают на родовое географическое наименование. Самой частотной реакцией стала лексема город (7).

Меньшее количество отвечающих связывают наименование города с достопримечательностями и с известными личностями, которые имеют отношение к Переславлю.

Интересно, что реципиенты воспринимают Переславль как зеленый город, находящийся в близости с лесом и природой. Таких реакций мы получили 3 \%. ций.

Отметим, что у $6 \%$ опрошенных данный стимул не вызвал никаких ассоциа-

Рассмотрим ассоциативные поля каждого стимула, составленные на основе реакций, полученных от молодых людей в возрасте от 18 до 25 лет.

\section{СРЕДНЯЯ ВОЗРАСТНАЯ ГРУППА \\ Ассоциативное поле топонима Углич}

Углич 41 - вода 7; город 4; ГЭС 3; ресторан; церковь 2; Аня одногруппница; Волга; грач; Дмитрий; игрушки; минералка; набережная; плотина; соревнования; угличская вода; уголь; уездный; флейта; царевич Дмитрий; час; ютюг 1.

Всего 34 реакции, из них различных - 21. Отказ - 7.

Ассоциативные реакции были распределены нами по семантическим группам, которые мы расположили в порядке убывания общего количества реакций:

1. Указание на городские объекты разного рода: ГЭС 3; ресторан; церковь 2; Волга; плотина; набережная 1.

Всего 10 реакций.

2. Связь с брендом питьевой воды: вода 7; минералка; Угличская вода 1.

Всего 9 реакций.

3. Родовое географическое наименование: город 4.

Всего 4 реакции.

4. Связь с историческим прошлым: Дмитрий; уездный; царевич Дмитрий 1.

Всего 3 реакции.

5. Реакции, которые сходны со стимулом по фонетической структуре: уголь 1.

Всего 1 реакция.

6. Связь с событиями разного рода: соревнования 1.

Всего 1 реакция. 
Реакции, связанные с конкретными личными впечатлениями и опытом испытуемых и не поддающиеся интерпретации: Аня одногруппница; грач; игрушки; флейта; час; ютюг 1.

Большее количество реакций $(4,1 \%)$ от респондентов этой возрастной группы указывает на городские объекты разного рода, наиболее частотной стала лексема ГЭС (3).

Реже участники эксперимента связывают Углич с родовым географическим наименованием, на что указывает количество полученных реакций - 1,64 \%. Также для языкового сознания небольшого числа опрошенных стали актуальными реакции Дмитрий, царевич Дмитрий, связанные с историческими событиями, происходившими в Угличе в XVII веке.

Опрошенные связывают топоним с существующими брендами пищевой продукции и питьевой воды. Таких реакций мы получили 3,69 \% от количества опрошенных.

Также мы получили единичные реакции, которые можно подвергнуть интерпретации. Такие ассоциации составили семантические группы, указывающие на связь топонима с различными событиями, с субъективной оценкой, эмоциями и впечатлениями. Также мы получили единичную реакцию, схожую с топонимом по фонетической структуре (уголь 1).

Стоит отметить, что у 2,87 \% опрошенных данный стимул не вызвал никаких ассоциаций.

\section{Ассоциативное поле топонима Тутаев}

Тутаев 40 - деревня; шоссе 3; автобус; город; далеко; декан; заводы; котлета; мясокомбинат; наркотики; остановка; остановка между Рыбинском и Ярославлем; плохо; по пути в Рыбинск; пригород; пряник; РГАТУ; речка; родственники; сестра; темно; туман; Тургенев; хурма 1.

Всего 28 реакций, из них различных - 24. Отказ - 12.

Ассоциативные реакции были распределены нами по семантическим группам, которые мы расположили в порядке убывания общего количества реакций:

1. Родовое географическое наименование: деревня 3; город; пригород 1.

Всего 5 реакций.

2. Связь названия города с городскими объектами, расположенными в Ярославле: шоссе 3; автобус; остановка 1.

Всего 5 реакций.

3. Эмоции, впечатления, субъективная оценка: далеко; наркотики; темно; туман; плохо 1.

Всего 5 реакций.

4. Указание на городские объекты разного рода: заводы; мясокомбинат; РГАТУ; речка 1.

Всего 4 реакции.

5. Указание на расположение города по отношению к другим населенным пунктам: остановка между Рыбинском и Ярославлем; по пути в Рыбинск 1.

Всего 2 реакции.

Реакции, связанные с конкретными личными впечатлениями и опытом испытуемых и не поддающиеся интерпретации: декан; котлета; пряник; родственники; сестра; Тургенев; хурма 1. 
На данный стимул от участников средней возрастной группы мы получили больше всего отказов. Это может говорить о том, что в языковом сознании молодых людей название города не вызывает никаких ассоциаций.

Реципиенты связывают топоним с родовым географическим наименованием, с эмоциями и субъективными впечатлениями в равной степени. Также мы получили реакции, которые характеризуют не сам стимул, а связь Тутаева с объектами в Ярославле. Это шоссе (предположительно, Тутаевское), остановка и автобус. Последние две ассоциации, вероятно, связаны Тутаевским шоссе, на котором объекты расположены. Можно также предположить, что данные ассоциации связаны с автобусной остановкой, где в Ярославле можно сесть на транспорт до Тутаева.

Также выявлены реакции, указывающие на расположение города на маршруте от Ярославля до Рыбинска.

\section{Ассоциативное поле топонима Переславль-Залесский}

Переславль-Залесский 50 - лес 3; озеро; Москва; церковь 2; Александр Невский; армия; архитектура; большая деревня; ботик; вокзал; горки; город; городок; далеко; дендрарий; друзья; история; Катя; коттеджи; красивый город; лагерь; лапти; медведь; небольшой город; недалеко; одноклассник; поездка; полпути; пряники; рождество; рыба; середина; синий камень; темный; холмистость; чаща; экскурсия 1.

Всего 42 реакции, из них различных - 37. Отказ - 8 .

Ассоциативные реакции были распределены нами по семантическим группам, которые мы расположили в порядке убывания общего количества реакций:

1. Связь названия города с природными объектами: лес 3; озеро 2; чаща; горки; холмистость 1.

Всего 8 реакций.

2. Указание на городские объекты разного рода: церковь 2; архитектура; ботик; вокзал; дендрарий; коттеджи; синий камень 1.

Всего 7 реакций.

3. Указание на расположение города относительно других населенных пунктов: далеко; недалеко; полпути; середина 1.

Всего 4 реакции.

4. Родовое географическое наименование: город; городок; небольшой город 1.

Всего 3 реакции.

5. Эмоции, впечатления, субъективная оценка: большая деревня; красивый город; темный 1.

Всего 3 реакции.

6. Связь с посещением города во время экскурсии: поездка; экскурсия 1.

Всего 2 реакции.

7. Связь с историческими событиями, с известными личностями: история; Александр Невский 1.

Всего 2 реакции.

8. Связь с другими населенными пунктами: Москва 2.

Всего 2 реакции.

9. Связь с символикой города, с гербом: рыба 1.

Всего 1 реакция.

Реакции, связанные с конкретными личными впечатлениями и опытом испытуемых и не поддающиеся интерпретации: армия; друзья; Катя; лагерь; лапти; медведь; одноклассник; пряники; рождество. 
Реципиенты данной возрастной группы связывают топоним с природными объектами. Эта семантическая группа стала самой объемной по количеству реакций, а самой частной стала ассоциация лес (3).

Также информанты отмечают различные городские объекты и достопримечательности. Интересно, что ярославцы отмечают удаленность города от центра области, и реакции полпути; середина 1, вероятно, говорят о расположении Переславля относительно Ярославля и Москвы.

В основном Переславль воспринимается участниками эксперимента как населенный пункт небольшого размера, встретились даже реакции, указывающие на размер города (городок; большая деревня; небольшой город 1).

Город интересен для экскурсионных поездок и своей историей, на что указывают ассоциации поездка; экскурсия; история; Александр Невский 1.

Интересно, что мы получили реакцию, указывающую на официальную символику города, а именно на герб Переславля, на котором изображены две золотые переславские ряпушки. Таким образом, реципиенты связывают топоним и с опознавательными знаками города.

Стоит отметить, что у 4,8 \% опрошенных данный стимул не вызвал никаких ассоциаций.

Рассмотрим ассоциативные поля каждого стимула, составленные на основе реакций, полученных от взрослых людей в возрасте от 26 до 80 лет.

\section{СТАРШАЯ ВОЗРАСТНАЯ ГРУППА \\ Ассоциативное поле топонима Углич}

Углич 38 - город 6; плотина 3; часы 2; Дмитрий; Институт сыроделия; Плещеево; большое каменное строение; вода; город в Яр. обл; дача; друг; друзья; история; красивый, уютный город; кровь; минеральная вода; мост; памятники архитектуры; плохая дорога до него; поселок; рядом с Ярославлем; сыр; царевич Дмитрий; часовой завод; часы «Чайка» 1.

Всего 33 реакции, из них различных - 25. Отказ - 5.

Ассоциативные реакции были распределены нами по семантическим группам, которые мы расположили в порядке убывания общего количества реакций:

1. Родовое географическое наименование: город 6; город в Яр. обл.; поселок 1.

Всего 8 реакций.

2. Связь с брендами продукции различного рода: часы 2; вода; минеральная вода; Институт сыроделия; сыр; часовой завод; часы «Чайка» 1.

Всего 8 реакций.

3. Указание на городские объекты разного рода: плотина 3; большое каменное строение; памятники архитектуры; мост 1.

Всего 6 реакций.

4. Связь с историческими событиями и легендой, связанной с городом: Дмитрий; царевич Дмитрий; кровь; история 1.

Всего 4 реакции.

5. Эмоции, впечатления, субъективная оценка: красивый, уютный город; плохая дорога до него 1.

Всего 2 реакции.

6. Связь с природными объектами: Плещеево 1.

Всего 1 реакция.

7. Указание на близость с Ярославлем: рядом с Ярославлем 1.

Всего 1 реакция. 
Реакции, связанные с конкретными личными впечатлениями и опытом испытуемых и не поддающиеся интерпретации: дача; друг; друзья 1.

Реципиенты старшей возрастной группы одинаково часто соотносят название города с родовым географическим названием и с брендами продукции различного рода. Таких реакций мы получили равное количество.

Ярославцы также отмечают связь города с городскими объектами, и наиболее распространенной ассоциацией в этой семантической группе стала плотина (3).

Встретилась единичная реакция Плещеево, скорее всего, реципиент допустил ошибку и связал озеро с Угличем, а не с Переславлем-Залесском. Возможно, в сознании респондента данные города Ярославской области смешиваются.

Также удалось выявить реакции, указывающие на историческое прошлое города, а именно на связь с известной легендой об убийстве царевича Дмитрия в Угличе. Реакцию кровь мы также отнесли к этой семантической группе, так как из истории известно, что именно на территории города свершилось убийство юного наследника престола.

Стоит отметить, что у 1,9 \% опрошенных данный стимул не вызвал никаких ассоциаций.

\section{Ассоциативное поле топонима Тутаев}

Тутаев 39 - город 4; завод; Романов-Борисоглебск 3; автобус; город рядом с Ярославлем; два светофора; зубодер; икона; красноармеец Тутаев; левобережный; левый берег; левый берег города; маленький; моторный завод; мясославль; НПЗ им. Менделеева; на двух берегах; овца романовская; пьянь; революционер; родня; светофор; с красивой набережной; хреново; шубы 1.

Всего 32 реакции, из них различных - 26. Отказ - 7.

Ассоциативные реакции были распределены нами по семантическим группам, которые мы расположили в порядке убывания общего количества реакций:

1. Указание на городские объекты разного рода: завод 3; моторный завод; мясославль; НПЗ им. Менделеева; с красивой набережной 1.

Всего 7 реакций.

2. Указание на расположение города: город рядом с Ярославлем; левобережный; левый берег; левый берег города; на двух берегах 1.

Всего 5 реакций.

3. Родовое географическое наименование: город 4.

Всего 4 реакции.

4. Связь с объектами, известными в городе: икона; овца романовская; шубы 1.

Всего 3 реакции.

5. Указание на историческое наименование города: Романов-Борисоглебск 3.

Всего 3 реакции.

6. Эмоции, впечатления, субъективная оценка: маленький; хреново; пьянь 1.

Всего 3 реакции.

7. Связь с известными личностями: красноармеец Тутаев; революционер 1.

Всего 2 реакции.

Реакции, связанные с конкретными личными впечатлениями и опытом испытуемых и не поддающиеся интерпретации: автобус; два светофора; зубодер; родня; светофор 1.

Тутаев в языковом сознании реципиентов старшей возрастной группы ассоциируется прежде всего с городскими объектами разного рода, популярны реакции, называющие предприятия и заводы. 
Интересно, что участники эксперимента отметили особенное расположение города, а именно на обоих берегах Волги. Реципиенты связывают Тутаев больше с частью, которая расположена на левом берегу реки.

Также взрослые люди помнят, что город до революции 1917 года имел другое название, об этом говорят реакции Романов-Борисоглебск, а также ярославцы отмечают революционера Тутаева в связи с современным названием города.

Удалось выявить синтагматические реакции - левобережный; маленький 1.

Стоит отметить, что у 2,45 \% опрошенных данный стимул не вызвал никаких ассоциаций.

\section{Ассоциативное поле топонима Переславль-Залесский}

Переславль-Залесский 35 - город 4; озеро; Плещеево озеро 3; ботик; камень 2; Александр Невский; город на горе; дорога М-8; дорога через лес; Лена; лес; лось; медведь; населенный пункт; Невский; ПЗ; Плещеево; по дороге в Москве; трасса М-8; церкви; ярославская область 1.

Всего 30 реакций, из них различных - 21. Отказ - 5.

Ассоциативные реакции были распределены нами по семантическим группам, которые мы расположили в порядке убывания общего количества реакций:

1. Связь с природными объектами: озеро 3; Плещеево озеро 3; Плещеево; лес; лось; медведь 1.

Всего 10 реакций.

2. Указание на городские объекты разного рода: ботик; камень 2; церкви 1.

Всего 5 реакций.

3. Родовое географическое наименование: город 4; город на горе; населенный пункт 1.

Всего 6 реакций.

4. Указание на дорогу до этого города: дорога M-8; дорога через лес; по дороге к Москве; трасса М-8 1.

Всего 4 реакции.

5. Связь с известными личностями: Александр Невский; Невский 1.

Всего 2 реакции.

6. Указание на принадлежность к Ярославской области: Ярославская область 1.

Всего 1 реакция.

7. Сокращенное наименование города: ПЗ 1.

Всего 1 реакция.

Реакции, связанные с конкретными личными впечатлениями и опытом испытуемых и не поддающиеся интерпретации: Лена 1.

Самой объемной по числу полученных реакций стала семантическая группа, указывающая на связь топонима с природными объектами. Респонденты ассоциируют Переславль-Залесский с Плещеевым озером (озеро 3; Плещеево озеро 3; Плещеево 1). Также для некоторого числа опрошенных данный город связан с родовым географическим названием и с дорогой, с трассой M8, которая проходит через населенный пункт.

Удалось выявить ассоциации, указывающие на полководца Александра Невского, который родился в Переславле-Залесском, и называющие сокращенное название населенного пункта (ПЗ 1). Участники эксперимента этой возрастной группы чаще всего дают парадигматические реакции.

Стоит отметить, что у 1,75 \% опрошенных данный стимул не вызвал никаких ассоциаций. 
Сопоставление полученных экспериментальных данных позволяет сделать следующие выводы:

1. Актуальными семантическими группами, которые мы выявили в ходе анализа ассоциативных реакций на топоним Углич, для всех возрастных категорий стали группы «Родовое географическое наименование», «Связь с брендами продукции различного рода».

2. Для младшей возрастной группы наиболее актуальны ассоциации, схожие с топонимом Углич по фонетической структуре; для реципиентов средней возрастной группы - реакции, указывающие на объекты разного рода; для старшей - ассоциации, указывающие на родовое географическое название.

3. Реципиенты младшей и средней возрастной категории связывают название города Углича со словами, сходными с топонимом по фонетической структуре, а участники эксперимента средней и старшей возрастной группы помнят об историческом прошлом города.

4. Актуальными семантическими группами, которые мы выявили в ходе анализа ассоциативных реакций на топоним Тутаев, для всех возрастных категорий стали группы «Родовое географическое наименование», «Эмоции, впечатления, субъективная оценка», «Указание на городские объекты разного рода».

5. Уникальными реакциями, актуальными только для младшей возрастной группы, стали ассоциации, объединенные в группы «Восприятие Тутаева как дома, родного места», «Интерпретация официального наименования города» и «Указание на другие топонимы»; реципиенты только средней возрастной категории указывают на расположение города по отношению к другим населенным пунктам, а информанты только старшего возраста упоминают историческое наименование Тутаева и известных в городе личностей.

6. Реципиенты всех возрастных групп дают реакции на топоним ПереславльЗалесский, которые можно объединить в такие семантические группы, как «Родовое географическое наименование», «Связь названия города с природными объектами», «Эмоции, впечатления, субъективная оценка», «Указание на городские объекты разного рода», «Связь с известными личностями».

7. Уникальными реакциями, актуальными только для младшей возрастной группы, стали ассоциации, называющие город местом, где много зелени, также только у учащихся топоним вызывает ассоциации со словами, сходными по фонетической структуре; реципиенты только средней возрастной категории указывают на расположение города по отношению к другим населенным пунктам и на символику города, а информанты только старшего возраста упоминают сокращенное наименование Переславля и вспоминают дорогу до этого города.

\section{Ссылки / References}

1. Белянин В. П. Психолингвистика. М.: Флинта, 2003.

2. Стернин И. А., Рудакова А. В., Виноградова О. Е. Проект «Значение как феномен языкового сознания (психолингвистическое значение слова)» // Вопросы психолингвистики. 2017. № 2 (32). С. 211-223.

3. Рудакова А. В. Специфика психолингвистического описания семантики топонимов

// Вестник ВГУ. Серия: филология и журналистика. 2019. № 1. URL:

http://www.vestnik.vsu.ru/pdf/phylolog/2019/01/2019-01-15.pdf 